\title{
Influência da temperatura de resfriamento sobre a variação mássica e resistência mecânica de ABS injetado
}

\author{
Influence of the cooling temperature on the mass \\ variation and mechanical resistance of injected \\ ABS
}

Fabiano Aparecido Silva ${ }^{1}$, Ronaldo Câmara Cozza ${ }^{1,2}$

\begin{abstract}
${ }^{1}$ CEETEPS - Centro Estadual de Educação Tecnológica "Paula Souza" - FATEC-Mauá - Departamento de Polímeros, Av. Antônia Rosa Fioravante, 804, CEP: 09390-120, Mauá, São Paulo, SP, Brasil.

${ }^{2}$ Centro Universitário da FEI - Fundação Educacional Inaciana "Padre Sabóia de Medeiros" - Departamento de Engenharia Mecânica, Av. Humberto de Alencar Castelo Branco, 3972, CEP: 09850-901, São Bernardo do Campo, São Paulo, SP, Brasil.

e-mail: ronaldo.cozza@fatec.sp.gov.br,rcamara@fei.edu.br
\end{abstract}

\section{RESUMO}

Peças de ABS injetadas e submetidas a diferentes temperaturas de resfriamento podem apresentar variações em sua massa e diferentes níveis de resistência mecânica. O objetivo deste trabalho é estudar a influência da temperatura de resfriamento sobre a variação mássica e resistência mecânica de peças produzidas em ABS por injeção. Com isso, inicialmente, corpos-de-prova em forma de engrenagem foram produzidos sob diferentes condições de resfriamento. Em seguida, a variação mássica dos corpos-de-prova foi analisada com o auxílio de uma balança analítica. Para a verificação da resistência mecânica do material estudado, foi projetado e construído um dispositivo mecânico, o qual possibilitou a aplicação de um carregamento ativo entre dois corpos-de-prova. Pelos resultados obtidos, foi possível observar que, com a diminuição da temperatura de resfriamento, houve um aumento de massa e resistência mecânica das peças injetadas.

Palavras-chave: ABS - Acrilonitrila Butadieno Estireno, temperatura de resfriamento, variação mássica, resistência mecânica.

\begin{abstract}
Injected ABS parts submitted to different cooling temperatures can present variations on their mass and different levels of mechanical resistance. The purpose of this work is to study the influence of the cooling temperature on the mass variation and mechanical resistance of injected ABS parts. Thereby, initially, specimen with gear shape have been produced under different cooling conditions. Then, the mass variation of the specimen has been analysed with the help of an analytical balance. To verify the mechanical resistance of the studied material, was designed and constructed a mechanical device, which made possible the application of an active loading on two specimens. By obtained results, it was possible observe that with the decrease of the cooling temperature, there was an increase on the mass and mechanical resistance of the injected ABS parts.
\end{abstract}

Keywords: ABS - Acrylonitrile Butadiene Styrene, cooling temperature, mass variation, mechanical resistance.

\section{INTRODUÇÃO}

A injeção de materiais poliméricos é uma técnica de processamento amplamente utilizada na indústria, devido à sua capacidade de transformação, o que possibilita a fabricação de peças em larga escala sob custos relativamente baixos [1].

Durante o processo de moldagem por injeção, o polímero se modifica devido às variações no ambiente termomecânico no qual se encontra, caracterizado por taxas de aquecimento, resfriamento e campos de tensões diversos [1]. Tais fatores provoca, na peça moldada, uma microestrutura heterogênea específica, caracterizada por uma variação gradual de 
sua morfologia, cristalinidade, orientação molecular e, consequentemente, de suas propriedades mecânicas finais [2].

À medida que o polímero fundido flui através do sistema, que compreende os canais de alimentação e a própria cavidade, as velocidades das camadas centrais se tornam maiores que as velocidades das camadas periféricas - próximas à parede do molde, devido ao arraste entre o fluido e as paredes do canal e à maior viscosidade de camadas externas, em razão do resfriamento oriundo das próprias paredes do molde [2-5].

As camadas centrais que apresentam velocidades relativamente elevadas são as primeiras a entrarem em contato com a parede fria do molde, solidificando-se e formando uma casca que tende a envolver toda a cavidade [2-5]. Como tais camadas são expostas a uma temperatura relativamente elevada, o grau de cisalhamento é relativamente baixo, ocasionando uma condição de orientação mínima; entretanto, as camadas subsequentes necessitam de um tempo maior para se solidificarem, visto que a casca inicial formada atua como um isolante térmico [2]. Com o tempo, tais camadas posteriores vão perdendo calor e, consequentemente, ficam mais viscosas; sob influência da pressão de injeção, este material viscoso continuará a fluir, embora mais vagarosamente do que as camadas centrais relativamente mais quentes [2-5]. Nestas condições, a tensão de cisalhamento atuante no material proporciona um elevado grau de orientação [2].

Quando a cavidade se encontra completa, o cisalhamento que atua no material cessa e as cadeias poliméricas orientadas relaxam, retornando a sua configuração inicial [2]. Porém, esta relaxação é retardada pelo aumento na viscosidade que ocorre rapidamente devido ao cisalhamento atuante e à perda de calor do molde [2]. Assim, a casca de material em contato direto com o molde manterá um baixo grau de orientação, pois já não é possível haver relaxação molecular; as camadas adjacentes, altamente orientadas, sofrerão relaxação parcial, em razão da temperatura de resfriamento, e o material situado na região central da cavidade apresentará um alto grau de relaxação, pois o calor é retido por um tempo relativamente maior [2].

Tal comportamento polimérico gera um gradiente de orientação molecular ao longo da secção transversal da peça, com valores mínimos reportados no centro da peça injetada e picos máximos nas laterais da mesma [3].

Em condições normais de processamento, sabe-se que a temperatura de resfriamento apresenta uma significativa influência sob a orientação molecular e, consequentemente, sob a massa e a resistência mecânica da peça injetada. Com isso, observando-se a relação exposta, o objetivo deste trabalho é estudar a influência da temperatura de resfriamento sob a massa e a resistência mecânica de ABS - Acrilonitrila Butadieno Estireno - injetado.

\section{MATERIAIS E MÉTODOS}

\subsection{Corpos-de-prova}

Inicialmente, foram produzidos corpos-de-prova de ABS (Acrilonitrila Butadieno Estireno) injetados em forma de engrenagem (Figura 1), seguindo o procedimento técnico descrito a seguir.

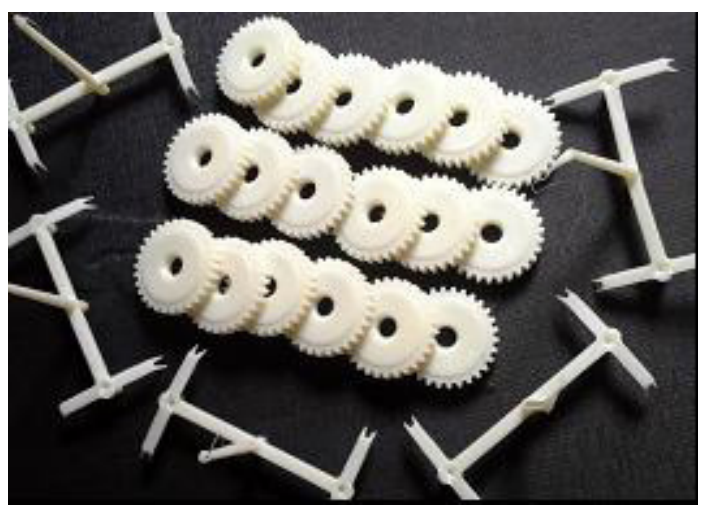

Figura 1: Corpos-de-prova de ABS (Acrilonitrila Butadieno Estireno) em forma de engrenagem.

Antes do processo de injeção propriamente dito, o ABS granulado foi devidamente acondicionado em uma estufa de secagem com temperatura controlada de $80^{\circ} \mathrm{C}$, durante um período de $4 \mathrm{~h}$, para que fosse eliminada toda a umidade do mesmo, conforme os procedimentos referentes às orientações técnicas recebidas do fabricante da resina de ABS (Basf Terluran ${ }^{\circledR}$ GP-22 ABS) utilizada neste trabalho.

Foi utilizada uma máquina-injetora da marca ROMI-Prática 170, sendo ajustada com temperatura na zona de aque- 
cimento entre $180^{\circ} \mathrm{C}$ e $220^{\circ} \mathrm{C}$ - seguindo-se as informações técnicas de processamento fornecidas pelo fabricante da resina de ABS (Basf Terluran ${ }^{\circledR}$ GP-22 ABS). Adicionalmente, também foram definidos e controlados a força de fechamento (170 tf), a pressão de injeção (1300 bar), o tempo de injeção (23 s) e a pressão de recalque (550 bar), de tal forma que todos estes parâmetros se mantivessem inalterados durante o processo de injeção, variando-se, somente, a temperatura de resfriamento dos corpos-de-prova.

Seguindo este procedimento, três diferentes níveis de temperatura de resfriamento dos corpos-de-prova foram definidos, conforme mostra a Tabela 1:

Tabela 1: Definição dos diferentes níveis de resfriamento dos corpo-de-prova de ABS injetados, em referência à "Condição de Resfriamento" e "Temperatura de Resfriamento".

\begin{tabular}{ccc}
\hline Nível de Resfriamento & Condição de Resfriamento & Temperatura de Resfriamento \\
\hline $1^{\circ}$ Nível de Resfriamento & $\begin{array}{c}\text { Injeção precedida por resfriamento com água res- } \\
\text { friada }\end{array}$ & Entre $20,8^{\circ} \mathrm{C}$ e $21,3^{\circ} \mathrm{C}$ \\
\hline $2^{\circ}$ Nível de Resfriamento & $\begin{array}{c}\text { Injeção precedida por resfriamento com água sob } \\
\text { temperatura ambiente }\end{array}$ & Entre $23,1^{\circ} \mathrm{C}$ e $24,6^{\circ} \mathrm{C}$ \\
\hline $3^{\circ}$ Nível de Resfriamento & $\begin{array}{c}\text { Injeção precedida por resfriamento sem utilização de } \\
\text { água - convecção natural }\end{array}$ & Convecção natural sob $28^{\circ} \mathrm{C}$ \\
\hline
\end{tabular}

\subsection{Análise da variação mássica dos corpos-de-prova}

Após serem injetados, as massas $(m)$ dos corpos-de-prova foram medidas, a fim de reportar-se as variações mássicas provocadas durante o processo de injeção em função da temperatura de resfriamento - " 1 " $2^{\circ}$ e $3^{\circ}$ Níveis de Resfriamento".

Tais medições de massa foram conduzidas em uma balança analítica com precisão de $0,001 \mathrm{~g}$, em uma sala ambiente com temperatura controlada de $21^{\circ} \mathrm{C}$.

\subsection{Análise da resistência mecânica dos corpos-de-prova}

A resistência mecânica do ABS também foi estudada em função da temperatura de resfriamento dos corpos-de-prova - " 1 , $2^{\circ}$ e $3^{\circ}$ Níveis de Resfriamento".

Inicialmente, análises pelo Métodos dos Elementos Finitos - MEF foram realizadas, com o objetivo de verificação da maneira pelo qual o ABS iria se deformar com a aplicação do torque durante os ensaios.

Após, para o estudo da resistência mecânica dos corpos-de-prova propriamente dito, um dispositivo de ensaio foi projetado (Figura 2a) e construído (Figura 2b). Neste dispositivo de ensaio, dois corpos-de-prova são engrenados, de forma que um permanece "fixo" e outro é "livre" para girar.
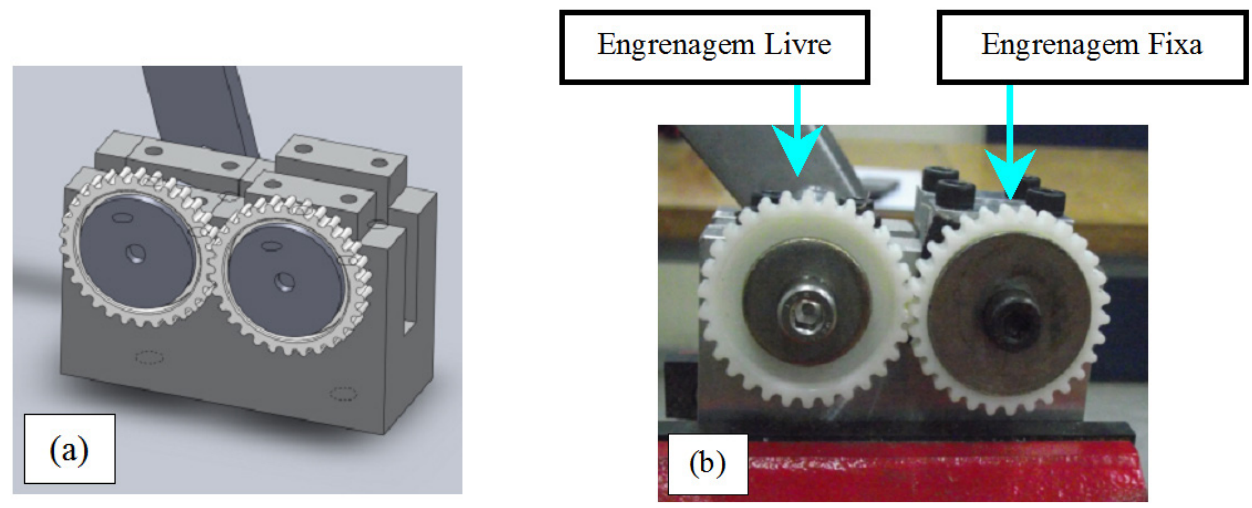

Figura 2: Dispositivo (a) projetado e (b) construído para a análise da resistência mecânica dos corpos-de-prova. 
Na engrenagem "livre" é acoplado um torquímetro de capacidade 245 N.m, como mostra as Figuras 3a-c. Em seguida, foi aplicado o torque $\left(T_{o}\right)$ necessário para que ocorresse a falha mecânica do corpo-de-prova; estes testes foram aplicados para cada um dos dentes das rodas dentadas.
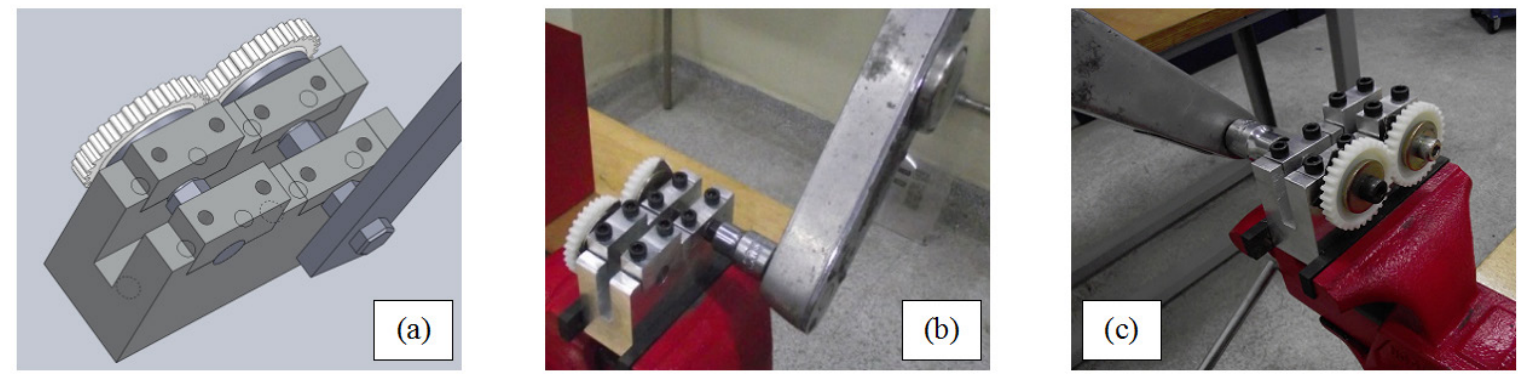

Figura 3: (a)-(c) Posição de acoplamento do torquímetro na engrenagem "livre".

\section{RESULTADOS E DISCUSSÃO}

\subsection{Orientação molecular do ABS}

A literatura [2-5] menciona que quanto menor a temperatura de resfriamento da peça de material termoplástico injetado, maior será a orientação molecular deste material, devido à maior taxa de cisalhamento gerada durante o preenchimento da cavidade. Por sua vez, a orientação molecular é o fator que determina a variação mássica e a resistência mecânica do ABS injetado, como serão discutidos nos Itens 3.2. e 3.3., respectivamente.

De forma esquemática e qualitativa, em função das diferentes temperaturas de resfriamento, os níveis de orientação molecular dos corpos-de-prova injetados para a realização deste trabalho podem ser representados pela Figura 4.

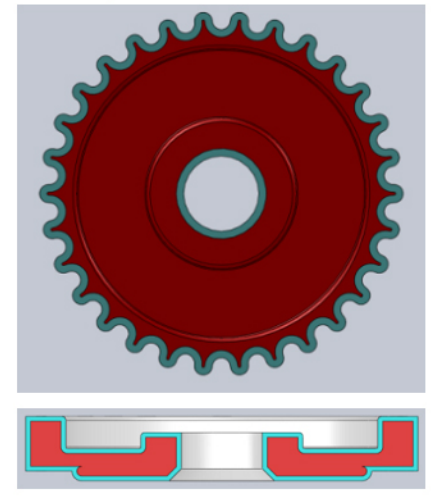

$1^{\circ}$ Nível de Resfriamento
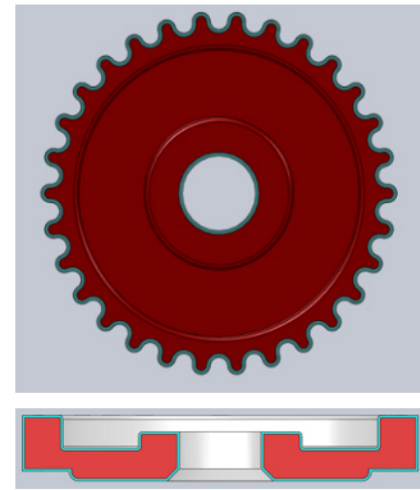

$2^{\circ}$ Nível de Resfriamento
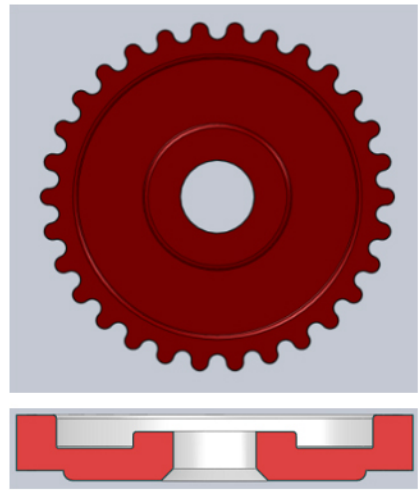

$3^{\circ}$ Nível de Resfriamento

Figura 4: Representações esquemáticas em vista superior e em corte-total dos diferentes níveis de orientação molecular em função da temperatura de resfriamento.

A figura em questão mostra que, com a diminuição da temperatura de resfriamento, é possível obter um volume maior de material com orientação molecular melhor definida (região verde). Em direção a região central dos corpos-de-prova, o tempo necessário para o resfriamento é maior, ocasionando níveis de orientação molecular relativamente menores (região vermelha).

\subsection{Análise da variação mássica do ABS}

A Figura 5 apresenta os valores de massa em função dos diferentes níveis de resfriamento.

Tais variações mássicas observadas são resultantes dos diferentes graus de orientação molecular dos corpos-de-prova, oriundos das diferentes temperaturas de resfriamento. Para menores temperaturas de resfriamento e próximo às paredes 
das cavidades, as cadeias poliméricas tendem a apresentar um melhor grau de alinhamento, resultando em uma redução das distâncias entre as próprias cadeias poliméricas e, consequentemente, um material relativamente mais denso, o que justifica os maiores valores de massas reportados para as menores temperaturas de resfriamento ( $1^{\circ} \mathrm{e} 2^{\circ}$ Níveis de Resfriamento).

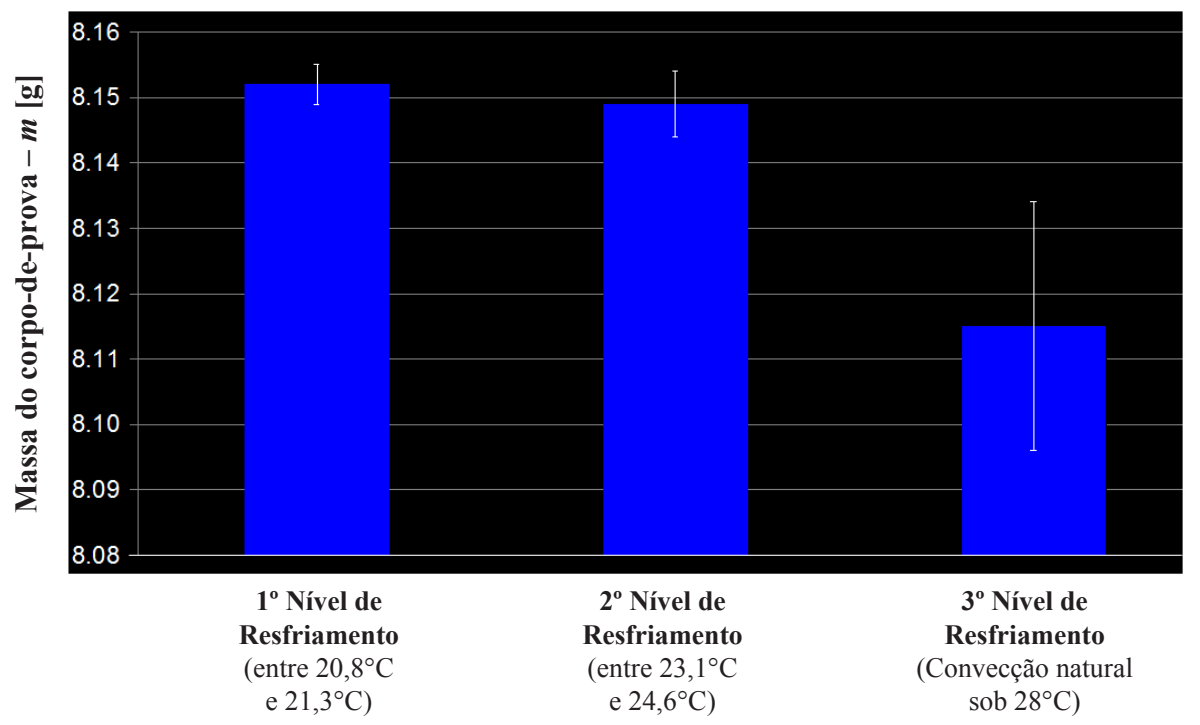

Figura 5: Variação mássica em função da temperatura de resfriamento.

\subsection{Análise da resistência mecânica do ABS}

A Figura 6 apresenta uma das simulações CAE conduzidas e, a Figura 7, o gráfico do torque $\left(T_{o}\right)$ em função da temperatura de resfriamento.

Nota-se que, com a diminuição da temperatura de resfriamento e, consequentemente, com o aumento do nível de orientação molecular, a resistência mecânica do ABS aumentou, caracterizado pelo maior torque suportável pelos corpos-de-prova.

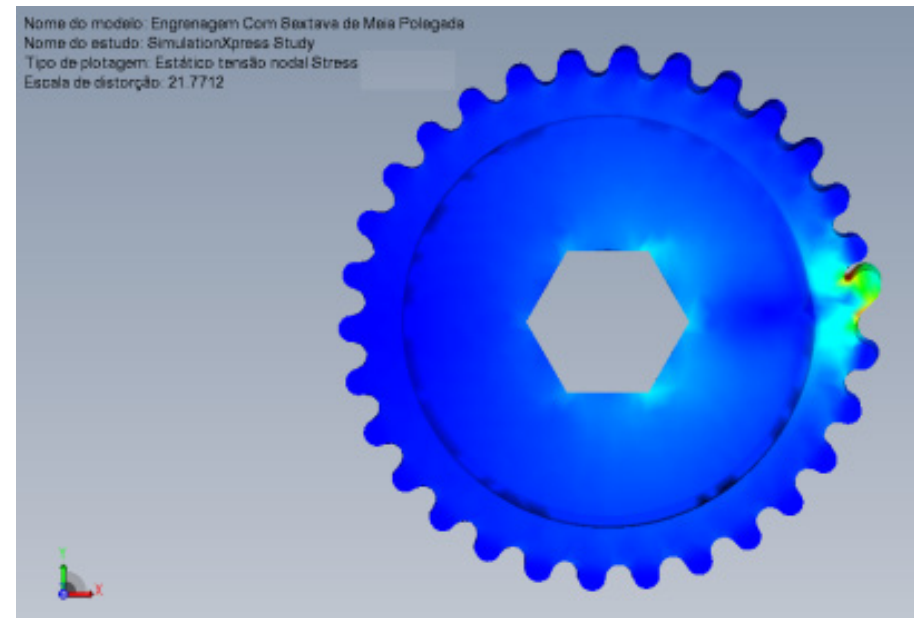

Figura 6: Simulação CAE dos corpos-de-prova. 


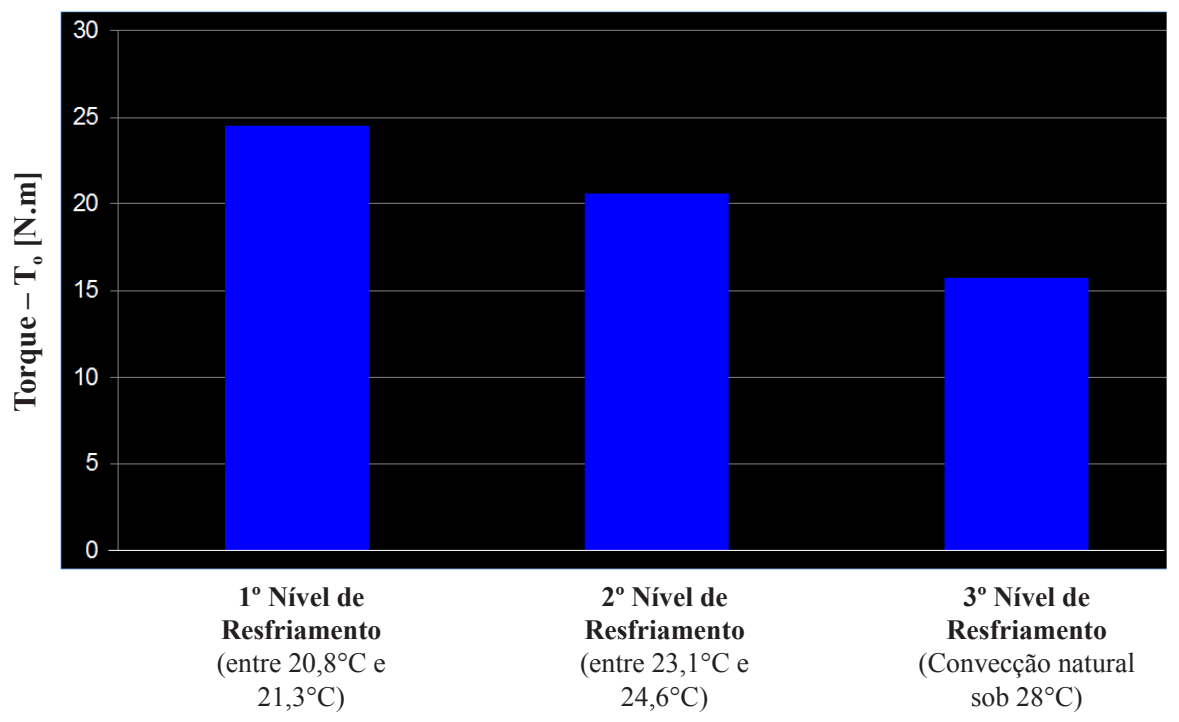

Figura 7: Comportamento do torque $\left(\mathrm{T}_{\mathrm{o}}\right)$ aplicado nos corpos-de-prova em função da temperatura de resfriamento. Maior Desvio-Padrão reportado: 1,5 N.m.

Tais variações mássicas observadas são resultantes dos diferentes graus de orientação molecular dos corpos-de-prova, oriundos das diferentes temperaturas de resfriamento. Para menores temperaturas de resfriamento e próximo às paredes das cavidades, as cadeias poliméricas tendem a apresentar um melhor grau de alinhamento, resultando em uma redução das distâncias entre as próprias cadeias poliméricas e, consequentemente, um material relativamente mais denso, o que justifica os maiores valores de massas reportados para as menores temperaturas de resfriamento ( $1^{\circ}$ e $2^{\circ}$ Níveis de Resfriamento).

\subsection{Relação entre massa e resistência mecânica em aplicações industriais}

Com os resultados obtidos nesta pesquisa, observou-se que, com a diminuição da temperatura de resfriamento, a massa de cada corpo-de-prova foi maior, acompanhada por uma maior resistência mecânica, devido ao melhor nível de orientação molecular conferido ao material injetado.

Por outro lado, quando se aumentou a temperatura para que o material fosse solidificado, reportou-se a diminuição da massa de cada corpo-de-prova, acompanhada, também, por um decremento na resistência mecânica, devido ao menor nível de orientação molecular do material injetado e resfriado.

Com isso, analisando-se as condições de solidificação do ABS, para componentes mecânicos que estarão sujeitos a um maior grau de solicitações mecânicas, provenientes de carregamentos externos, é importante estabelecer valores menores de temperaturas de resfriamento, pois estas proporcionam maiores valores de resistências mecânicas para a peça projetada.

Para peças cujos direcionamentos de projeto são em aplicações sob solicitações mecânicas externas relativamente baixas, não apresentando, consequentemente, um risco eminente de falha, pode-se adotar temperaturas maiores necessárias à solidificação do material. Esta opção técnica acarretará a fabricação de componentes mecânicos de ABS com menor resistência mecânica, mas, em contrapartida, em função da quantidade de peças a serem produzidas, pode-se conseguir uma economia significante de material injetado. Por exemplo, para o componente mecânico estudado neste trabalho, injetado sob as condições de fabricação aqui estabelecidas, em um lote de 10 milhões de peças, que é um valor quantitativo de produção comum no ramo de transformação de materiais poliméricos, classificado com "produção de larga escala", a diferença de material injetado pode atingir a ordem de 210 toneladas.

\section{CONCLUSÕES}

Com os resultados obtidos nesta pesquisa, conclui-se que:

1) A massa e a resistência mecânica de um componente polimérico de ABS injetado depende da temperatura na qual o mesmo é solidificado;

2) A adoção de menores temperaturas de solidificação caracteriza o componente de ABS injetado por apresentarem: 
- Maior massa;

- Maior resistência mecânica.

3) A adoção de maiores temperaturas de solidificação ocasiona ao componente de ABS injetado e ao sistema produtivo:

- Menor massa;

- Menor resistência mecânica;

- Economia de material.

Logo, "maior" ou "menor" massa e, consequentemente, "maior" ou "menor" resistência mecânica, respectivamente, podem ser obtidas em função da temperatura de resfriamento do componente de ABS injetado.

Com isso, esta pesquisa é finalizada concluindo-se que não existe um valor de temperatura "ideal" sob a qual o material polimérico de ABS é solidificado, após o processo de injeção. Na realidade, este fator é uma condição técnica que deve ser definida pelos profissionais qualificados responsáveis pelo projeto e fabricação do componente mecânico, em função de sua aplicação na área, de forma a contemplar a "resistência mecânica" ou a "economia de material".

\section{AGRADECIMENTOS}

Os autores agradecem aos Professores Carlos Fernandes da Silva e Marcos Oliveira Gentil pela ajuda com as injeções dos corpos-de-prova.

\section{BIBLIOGRAFIA}

[1] ALMEIDA, Á.M., BRANCIFORTI, M.C., BRETAS, R.E.S., “Avaliação da orientação molecular de moldados de polipropileno utilizando figuras de pólo obtidas por difração raios-X”, Revista Polímeros: Ciência e Tecnologia, v. 17, n. 1, pp. 28-35, 2007.

[2] HARADA, J. Moldes para Injeção de Termoplásticos, $1^{\text {a }}$ Edição, Brasil, Editora Artliber, ISBN 978-8-58-809818-3, 2008.

[3] TADMOR, Z., GOGOS, C. G. Principles of Polymer Processing, $2^{\text {nd }}$ Edition, United States of America, WILEY-INTERSCIENCE - A John Wiley \& Sons, Inc., Publication, ISBN 0-471-38770-3, 2006.

[4] MANRICH, S. Processamento de Termoplásticos, 2a Edição, Brasil, Editora Artliber, ISBN 978-8-58-809872-5, 2013.

[5] SORS, L., BARDÓCZ, L., RADNÓTI, I. Plásticos - Moldes e Matrizes, $3^{a}$ Edição, Hungria, Editora Hemus, ISBN 978-8-52-890019-4, 2006.

\section{ORCID}

Fabiano Aparecido Silva

Ronaldo Câmara Cozza https://orcid.org/0000-0002-4310-1202

https://orcid.org/0000-0002-4880-4791 